\title{
机械外力下动力电池包的系统安全性分析与评价 ${ }^{*}$
}

\author{
李志杰 ${ }^{1,2}$ 陈吉清 ${ }^{1,2}$ 兰凤崇 ${ }^{1,2}$ 郑文杰 ${ }^{1,2}$ \\ (1. 华南理工大学机械与汽车工程学院 广州 510640; \\ 2. 广东省汽车工程重点实验室 广州 510640)
}

\begin{abstract}
摘要: 动力电池包是一个复杂系统综合体, 对复杂系统而言仅考虑组件的可靠安全性并不能保证其系统的安全性, 迫切需要 从系统层面分析评价动力电池包的安全性。运用复杂系统安全理论结合电动汽车实际工况, 提出基于整体精细化模型可量化、 层次化的动力电池包系统安全性评价。保证单体锂电池模型精细化的情况下, 从正碰、侧碰、振动冲击三种常见工况对动力 电池包进行仿真分析, 采用层次分析(AHP)和模糊综合评价(FCE)相结合的方法对影响动力电池包系统安全的关键因素指标进 行综合性安全评价。结果表明动力电池包系统安全性等级较低, 安全性能较差。所提方法可为动力电池包正向结构设计和系 统安全改善等工作提供参考。
\end{abstract}

关键词: 动力电池包; 复杂系统安全; 精细化模型; 评价方法

中图分类号: TG156

\section{Analysis and Evaluation on System Safety of Power Battery Pack under Mechanical Loading}

\author{
LI Zhijie $^{1,2}$ CHEN Jiqing ${ }^{1,2}$ LAN Fengchong ${ }^{1,2}$ ZHENG Wenjie ZH, $^{1,2}$ \\ (1. School of Mechanical \& Automotive Engineering, South China University of Technology, \\ Guangzhou 510640; \\ 2. Guangdong Provincial Key Laboratory of Automotive, Guangzhou 510640)
}

\begin{abstract}
Power battery packs are complex system wholes. For complex systems, considering only the reliable safety of components does not guarantee the safety of their systems. It is urgently needed to analyze and evaluate the safety of power battery packs from the system level. Using the theory of complex system safety combined with the actual working conditions of electric vehicles, a quantifiable and hierarchical system safety evaluation of power battery pack is proposed based on the whole refinement model. To ensure that the model of the lithium-ion cells is refined, the power battery pack is simulated and analyzed from three common working conditions, such as positive collision, lateral collision and vibration impact, and the key factors affecting the system safety of power battery pack are comprehensively evaluated by the method of hierarchical analysis(AHP) and fuzzy comprehensive evaluation (FCE). The results show that the system safety of power battery pack has low level, and safety performance is poor. The method can provide reference for the forward structure design and system safety improvement of power battery pack.
\end{abstract}

Key words: power battery pack; complex system safety; integrated refinement model; evaluation method

\section{0 前言}

动力电池包作为电动汽车的核心, 其安全性备 受关注。大量事故调查显示, 电动汽车爆炸起火基 本都是由于电池包内部产生了严重的安全问题所导 致, 因此解决动力电池包的安全问题是当前电动汽 车发展迫切需要的。动力电池包由众多部件组成,

* 国家重点研发计划资助项目(2018YFB0104100)。20180522 收到初稿, 20190221 收到修改稿
在结构组成上具有一定的复杂性。当电动汽车在随 机路况下作业时, 电池包内部会受到机械-电-热三 种相互耦合的场作用, 其安全性是一个系统层面属 性, 即一种整体涌现性。因此, 动力电池包的安全 性研究需要从系统层面认知 ${ }^{[1-3]}$ 。

目前国内外研究人员对动力电池包的安全问题 主要集中在单体电池材料改善、电安全的控制电路 和控制策略的设计、电池包在滥用条件下的热安全 性能的提升以及电池壳体、电池架的耐撞性和模态 特性等方面 ${ }^{[4-8]}$ 。例如: 孙小卯 ${ }^{[7]}$ 采用结构优化方法 
增强了动力电池包的疲劳寿命。张立军等 ${ }^{[8]}$ 根据振 动冲击对电池耐久性和安全性的影响, 从试验检 测、建模分析、设计与控制措施等方面进行研究。 然而, 目前的研究基本都是针对单一组件的可靠安 全性, 缺乏系统安全的概念。复杂系统安全理论认 为组件可靠性增加到某种程度以后就不能显著增 加系统安全性, 也就是说所有组件都十分可靠时, 系统结构也可能发生崩溃 ${ }^{[9]}$, 因此仅通过提升电池 包内各组件的可靠安全性, 并不能改善其系统安全 性。采用复杂系统认知下的电池包安全性研究与评 价方法, 不仅考虑各组件的可靠安全性, 组件之间 的潜在耦合关系也要考虑 ${ }^{[10]}$, 但这种关系非常复 杂, 难以通过理论分析产生, 因此将整个电池包作 为研究对象, 构建一个整体精细化模型。模型包含 若干个子系统, 子系统由多个组件构成, 通过整体 模型反映出整个动力电池包结构的复杂化、层次 化、组元化。

外部环境(事件)是引发动力电池包产生安全问 题的主要因素, 根据近年的事故调查发现电动车行 驶过程中, 电池包的安全威胁主要来源两个方面。

(1) 碰撞。碰撞会给电池包带来巨大的冲击, 使内部的单体电池和模组产生过大的加速度, 很可 能会损坏焊点等连接件, 造成电池松动、窝动, 从 而引起电池异常发热、短路甚至热失控。此外, 碰 撞导致电池包挤压变形的同时也会造成模组及单体 电池变形, 有可能损坏电池内部隔膜引发严重的热 事件。

（2）振动冲击。复杂路面激励下, 电池包由于 自身结构设计缺陷或电池质量分布不合理导致触点 位置动力学响应过大, 引起输出电压、电流变化导 致安全性问题, 或在长时间随机激励下电池包内部 发生疲劳损坏, 失去对电池的保护作用, 进而导致 电池触点脱离或局部短路、高压漏电等危险情况的 产生。

外界环境对动力电池包系统安全所产生的两种 状态都是机械外力造成的, 碰撞属于突发状态, 伤 害最为严重; 振动冲击属于演化状态, 虽然不会短 时间内产生安全问题, 但是长期的工作老化可能导 致系统安全性下降 ${ }^{111}$ 。针对动力电池包系统安全在 机械外力作用下的分析与评价, 首先构建动力电池 包精细化有限元模型, 模型通过了试验的验证; 其 次通过正面碰撞、侧面碰撞及振动冲击三种工况对 动力电池包模型进行仿真分析, 提出影响系统安全 的关键因素指标; 最后综合三种工况下的关键因素 指标, 运用层次分析法结合模糊综合评价对其进行 了系统安全性评价。

\section{1 动力电池包系统安全的复杂性分析}

描述一个复杂系统需包含系统外部环境(事 件)、系统边界、内部组成元素、元素间的关联以及 整体涌现这几个部分, 如图 1 所示。假设复杂系统 $S$ 中, 所有组成元素的集合为 $A=\left\{A_{1}, A_{2}, \cdots, A_{n}\right\}$, 它 们之间所有关联关系的集合为 $R=\left\{R_{1}, R_{2}, \cdots, R_{n}\right\}$, 则 复杂系统简化形式表达表述如下

$$
S=\langle A, R\rangle
$$

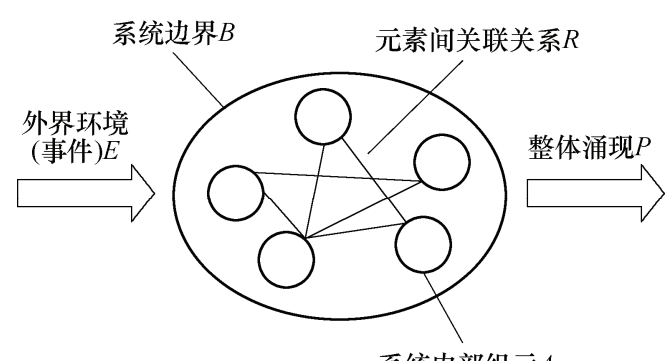

系统内部组元 $A$

图 1 复杂系统逻辑图

外部环境(事件)的表达方式如下

$$
X=\{x \mid x \in E\}
$$

式中 $x$ 一外部环境因素;

$E$ 一一所有因素的集合。

大量事故调查表明, 影响动力电池包系统安全 最为显著的两个因素：碰撞和振动冲击。因此, 外 部环境的表达式写为

$$
X=\left\{x_{1}, x_{2}\right\}
$$

式中 $x_{1}$ 一碰撞;

$x_{2}$ 一振动冲击。

整个动力电池包 $A_{B}$ 内部组成元素可以分为四 个部分，表达为

$$
A_{B}=\left\{A_{1}, A_{2}, A_{3}, A_{4}\right\}
$$

式中 $A_{B}$ 一动力电池包系统;

$A_{1}$ 一包括所有单体电池的电池子系统;

$A_{2}$ 一包括电池模块的模组子系统;

$A_{3}$ 一包括上下壳体、内架、压杆、压盖等 的壳体子系统;

$A_{4}$ —包括测温元件、控制电路等的电池管 理子系统。

组件之间所有的关联关系如下

$$
R=\left\{R_{1}, R_{2}\right\}
$$

式中 $R_{1}$ 一物理连接, 即强作用连接, 包括预紧 连接、焊接连接等; 
$R_{2}$ 一化学连接, 即弱作用连接, 包括温 度场、机械场、电磁场的相互耦合作 用等。

根据上述分析, 动力电池包复杂系统逻辑图可 以定义如下。

根据图 2 可知, 组件之间物理连接和化学连接 同时存在，因此潜在的耦合关系对电池包的影响不 可忽略。动力电池包系统安全性与组件之间的可靠 安全性的关系如图 3 所示, 可靠性的持续增长在一 定程度上提高了系统安全性, 但可靠性到达某一临 界值后，继续增加对于系统安全性的提高没有任何 帮助 ${ }^{[12-13]}$ 。这很好地解释了动力电池包各个组件都 安全可靠, 装配之后依然会存在安全隐患。因此, 需要从系统层面针对动力电池包的安全进行分析和 评价。

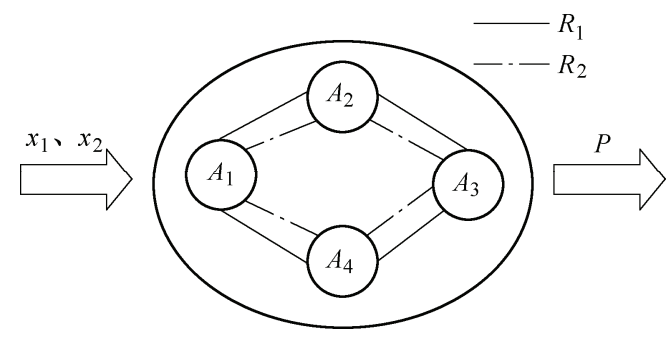

图 2 动力电池包复杂系统逻辑图

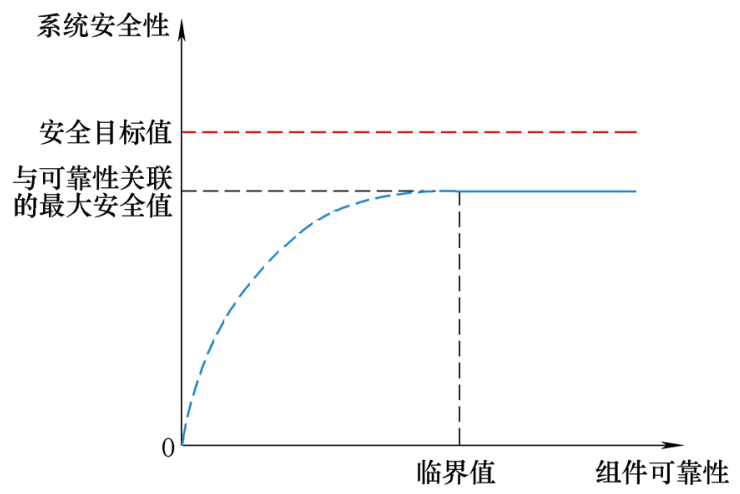

图 3 可靠性与安全性对比图

\section{2 机械外力下动力电池包的系统安全 性仿真分析}

\section{1 动力电池包整体精细化有限元模型构建}

目前大部分单体锂电池的模型都是采用刚体模 拟, 不能真实反映电池的变形情况, 还会增加电池 模组的冲击速度, 导致整体仿真误差变大。锂电池 内部结构复杂, 由正负极片和隔膜相互堆叠而成, 建模时需要进行简化。整个内芯在挤压过程中所提 供的阻力基本都来源于极片的涂层材料, 因此采用 可压缩性泡沫材料代替内芯材料 ${ }^{[14-16]}$, 芯层通过六
面体单元划分, 壳体利用壳单元划分, 有限元模型 如图 4a 示。然后根据电池的串并联方式将单体电池 模型装配成整体动力电池包模型, 如图 $4 \mathrm{~b}$ 所示, 其 中螺钉和上压盖因为结构复杂而采用四面体单元, 其余壳体部件采用壳单元。划分网格最小单元尺寸 $1 \mathrm{~mm}$, 共 349164 元, 实体单元 117113 个, 节点 266441 个, 最小雅克 0.5 , 满足计算要求。由于电 池包内部组件的重力和预紧螺栓力会产生预应力 场, 预应力场会影响整个电池包的固有频率, 因此 动力电池包模型必须考虑螺栓预紧力、表面接触刚 度和摩擦因数 ${ }^{[17-18]}$, 以保证模型的精准性。

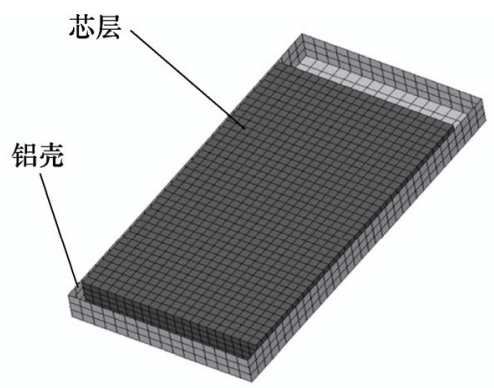

(a) 单体电池有限元模型

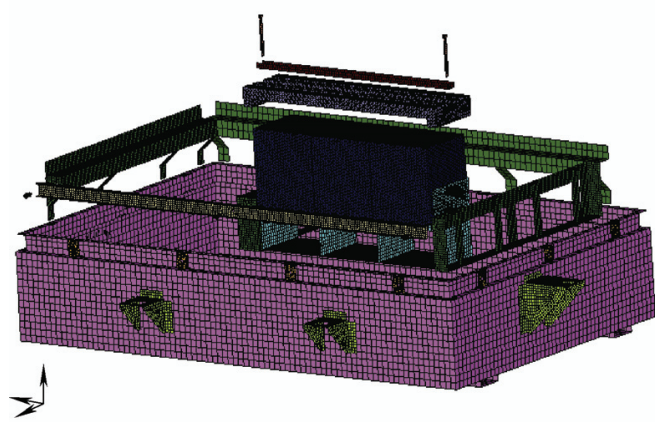

(b) 动力电池包有限元模型

图 4 动力电池包整体有限元模型

\section{2 机械外力下动力电池包系统安全性的研究分析}

机械外力下动力电池包系统安全所面对的两种 状态分别为碰撞和振动冲击, 而碰撞具体可分为正 碰、侧碰及后碰(追尾), 其中前两种碰撞对动力电池 包的伤害最为严重。根据上述情况, 机械外力对动力 电池包产生的三种工况被设定为: 正碰、侧碰及振动 冲击。在交通事故中, 侧碰撞击受力面积小, 车辆侧 面吸能空间有限, 变形侵入量更大, 对电池包的威胁 也更大。因此, 先针对侧面碰撞进行仿真分析。

\subsection{1 侧碰状态的仿真分析}

根据欧洲 NCAP 传统汽车侧面刚性柱碰撞试验 标准进行一定的调整改进, 侧面碰撞的刚性柱直径 为 $254 \mathrm{~mm}$, 其顶端到碰撞车辆顶部垂直距离为 100 $\mathrm{mm}$, 底端到碰撞车辆门槛底部垂直距离为 $102 \mathrm{~mm}$ 。 侧面碰撞速度为 $29 \mathrm{~km} / \mathrm{h}$, 方向与车辆纵轴垂直, 如 图 5 所示。下面从最大应力、弯曲变形以及加速度 
三个方面对动力电池包的系统安全问题进行分析。

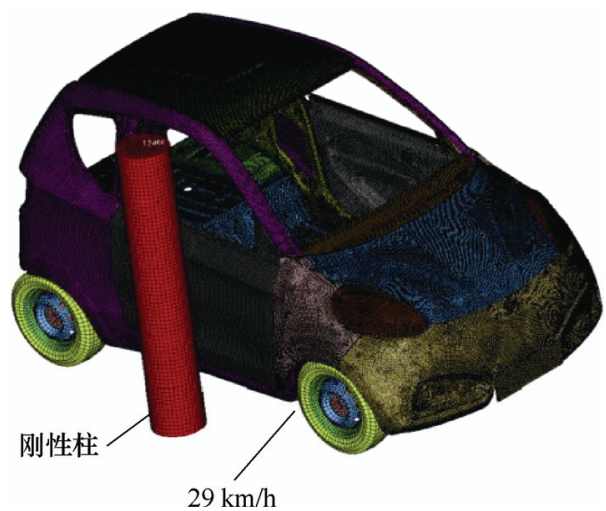

图 5 电动汽车整车刚性柱侧面碰撞有限元模型

\subsubsection{1 最大应力}

侧面碰撞对动力电池包 7 个吊耳产生较大应 力, 如果吊耳应力过大导致断裂, 会引起电池包跌 落进而造成电池包二次伤害。根据仿真从碰撞开始 到结束 $100 \mathrm{~ms}, 7$ 个吊耳的应力变化如图 6 所示, 吊耳应力变化趋势一致, 应力值峰值主要集中在 30 65 ms 期间。吊耳 1 靠近碰撞区, 其应力峰值 较大, 达到 $478.9 \mathrm{MPa}$, 产生了明显的塑性变形, 吊耳 3 整个碰撞过程中其应力值均略小于其他吊 耳。从电池包吊耳应力分布角度考虑, 吊耳分布较 为合理, 但电池包吊耳整体应力峰值过高, 除吊耳 3 以外, 均超过了 $300 \mathrm{MPa}$, 逼近 Q235 钢材料的抗 拉强度值 $400 \mathrm{MPa}$ ，存在断裂的危险。

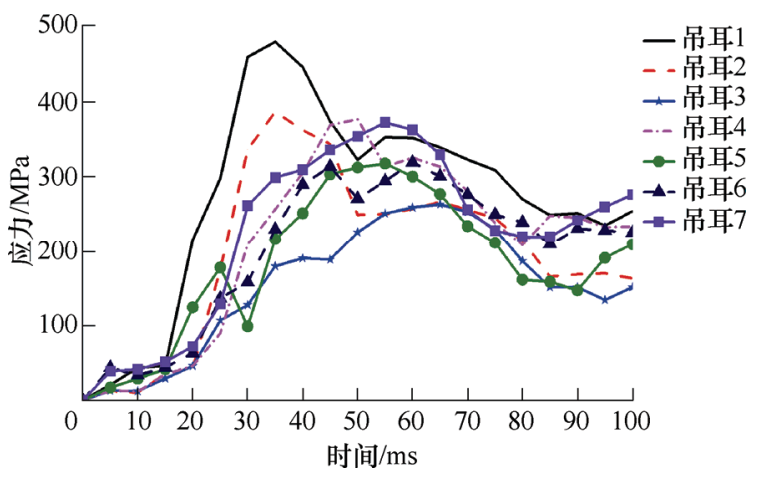

图 6 动力电池包吊耳应力变化图

侧面碰撞导致电池包内部预紧螺钉发生变形弯 曲, 如若变形过大, 很可能造成失效, 螺钉失效会 失去对电池模组的约束, 导致危险事故的产生。如 图 7 所示, 其中螺钉 2 在整个碰撞过程中最大应力 达到了 $452.6 \mathrm{MPa}$ ，螺钉 6 和 7 也超过了 $410 \mathrm{MPa}$, 由于螺钉的断裂强度 $400 \mathrm{MPa}$, 此处存在严重的风 险问题。壳体焊接处位置的应力基本都没有超过壳 体材料的屈服强度，因此没有破坏的危险性。

\subsubsection{2 弯曲变形}

如图 8a 可知, 电池包左侧吊耳处位置在碰撞情

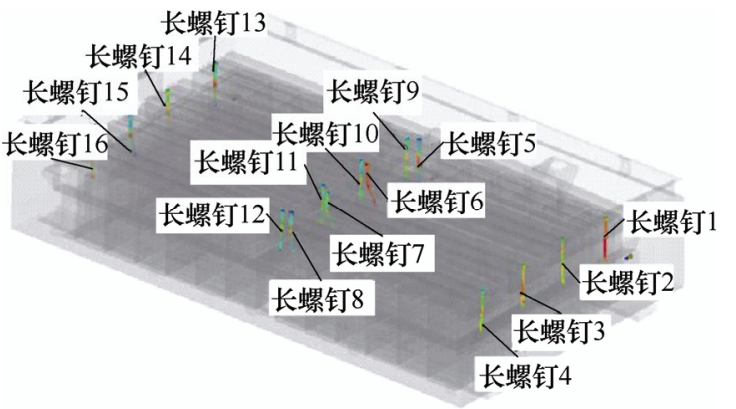

图 7 动力电池包预紧螺钉碰撞变形图

况下产生了较大侵入量。由于被撞击处非常接近电 池模组, 壳体较大侵入量导致电池模组被严重挤压, 产生安全隐患。图 $8 \mathrm{~b}$ 显示动力电池包内架受到了壳 体侵入的挤压, 内架左侧与右侧有较明显的弯曲变 形，中间架虽然弯曲不明显，但是有向右倾斜的趋势。 图 $8 \mathrm{c}$ 可知, 碰撞导致动力电池包上压盖发生了较大 的水平滑移, 这就直接导致连接压盖和内架的螺栓产 生了弯曲变形, 图 $8 \mathrm{~b}$ 中圈出的螺栓变形较为严重。

碰撞事故中造成爆炸起火的原因大多来至于单 体电池和电池模组, 所以电池系统的安全性尤为重 要, 图 $8 \mathrm{~d} 、 8 \mathrm{e}$ 中电池模组在侧面碰撞下的最大变形 位置为 $A$ 和 $B$, 其中位置 $A$ 处变形量达到最大值 $12.58 \mathrm{~mm}$, 根据文献[19]提出的电池模组安全变形 量为初始尺寸的 $10 \%$, 整体模型中电池模组在挤压 变形之前的初始尺寸为 $131 \mathrm{~mm}$, 因此最大变形量即 为 $13.1 \mathrm{~mm}$, 由此可知电池模组 $A$ 位置的变形量 $12.58 \mathrm{~mm}$ 接近最大变形量 $13.1 \mathrm{~mm}$, 存在一定的安 全隐患。此外, 模组 $B 、 C$ 由于碰撞导致上下跳动, 跳动量达到了 $15 \mathrm{~mm}$ 。

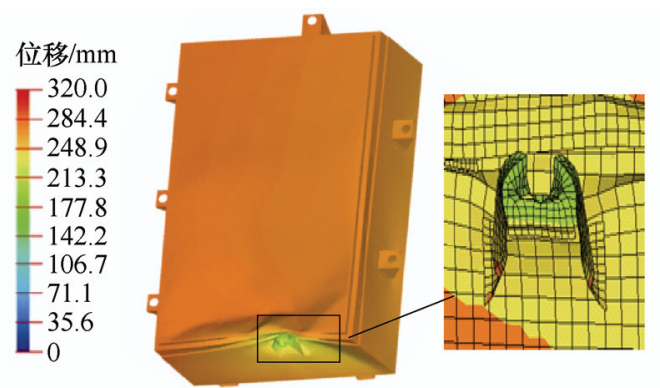

(a) 壳体入侵量

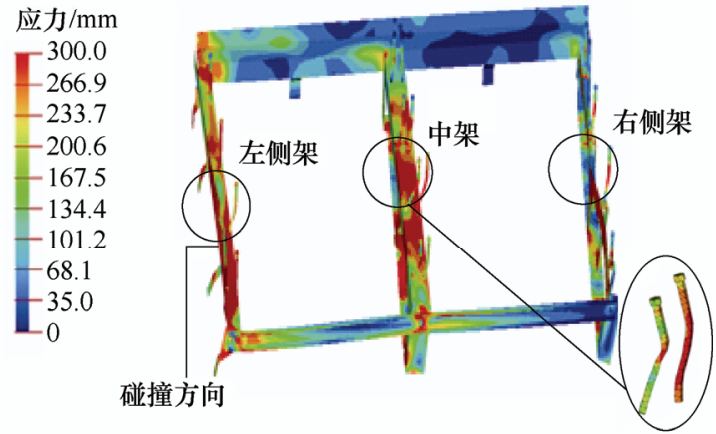

(b) 内架弯曲变形 


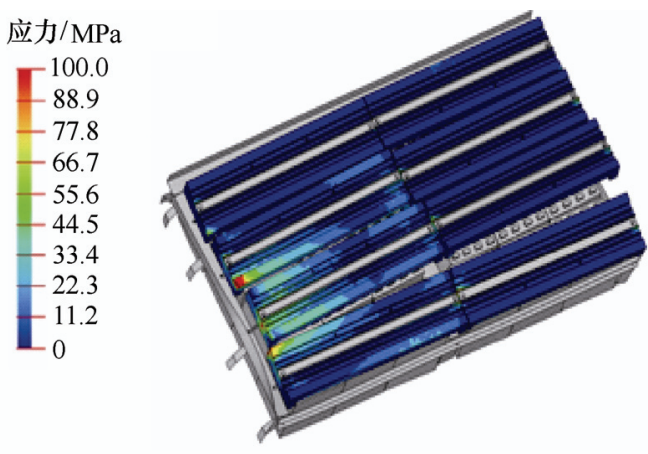

(c) 电池模组滑移
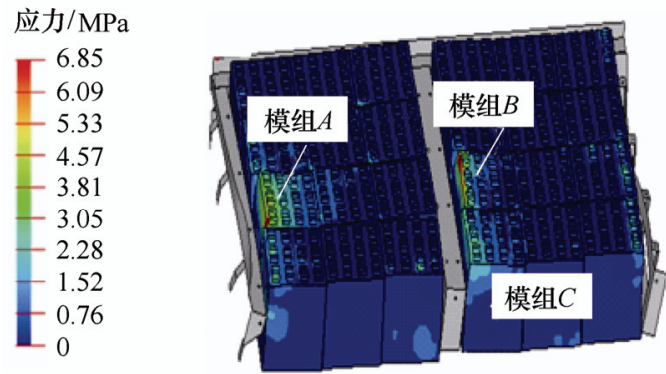

(d) 电池模组挤压变形

应力 $/ \mathrm{MPa}$

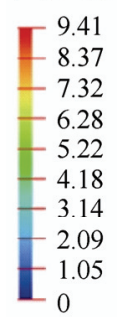

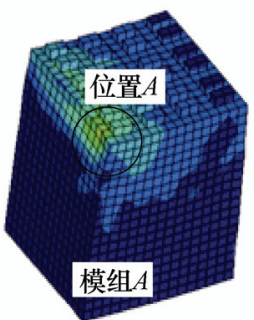

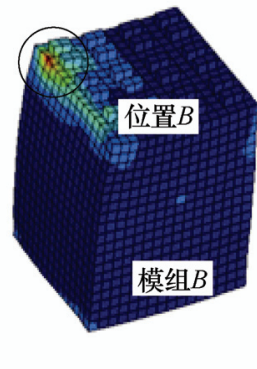

(e) 电池模组变形最大位置
图 8 碰撞状态下动力电池包内部组件变形分析

\subsubsection{3 加速度分析}

电池模组是由 12 块单体电池并联构成, 连接方 法为电池单体正负极极耳与铜片通过激光拼焊, 且 铜片还与上压盖通过螺钉紧固连接(图 9)。碰撞导致 电池单体正负极极耳加速度增大, 会产生很大的惯 性冲击, 对电池单体正负极极耳与铜片的连接造成 威胁。如果极耳与铜片连接失效, 会使得电池单体 正负极接触, 造成电池单体外部短路危险。

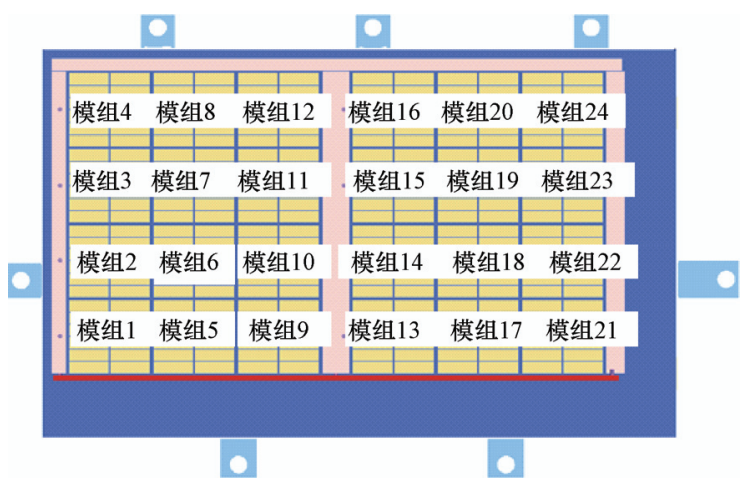

图 9 动力电池包模组分布示意图
电池包内部共包括 24 个电池模组, 288 块单体 电池。整个碰撞过程中每个模组的加速度都是由相 应单体电池加速度的最大值的平均值产生, 并以此 表征该电池模组在碰撞过程中的加速度响应。表 1 所示, 24 个电池模组中加速度最大的是模组 21 , 加 速度值为 $119.2 \mathrm{~g}$ 模组 $17 、 22$ 的加速度值也超过了 $100 g$ 。根据文献 $[20]$ 可知, 模组可以承受的最大加 速度为 $35 \mathrm{~g}$ 或者半正弦波冲击持续脉冲时间 $51 \mathrm{~ms}$, 碰撞产生的瞬时加速度脉冲时间要短于 $51 \mathrm{~ms}$ 的持 续时间, 并且最大加速度峰值是其 3 倍多, 过大加 速度可能导致动力电池包内部电池模组触点松动、 脱落或者电器附件脱落等, 进而引发短路造成安全 事故。

表 1 侧面碰撞过程中各电池模组加速度最大值

\begin{tabular}{cc||cc||cc}
\hline 编号 & 加速度 $/ g$ & 编号 & 加速度 $/ g$ & 编号 & 加速度 $/ g$ \\
\hline 1 & 62.8 & 9 & 81.4 & 17 & 103.3 \\
2 & 68.4 & 10 & 79.5 & 18 & 97.2 \\
3 & 48.8 & 11 & 70.2 & 19 & 85.1 \\
4 & 48.1 & 12 & 44.2 & 20 & 62.8 \\
5 & 69.7 & 13 & 102.8 & 21 & $\mathbf{1 1 9 . 2}$ \\
6 & 71.4 & 14 & 95.9 & 22 & 100.0 \\
7 & 59.4 & 15 & 83.7 & 23 & 85.3 \\
8 & 63.6 & 16 & 61.8 & 24 & 57.1 \\
\hline
\end{tabular}

\subsection{2 正碰状态的仿真分析}

参照 《GB11551-2003 乘用车正面碰撞的乘员保 护》和 C-NCAP 评价规程, 建立正面 100\%的刚性 墙碰撞有限元模型如图 10 所示, 模型中碰撞速度为 $50 \mathrm{~km} / \mathrm{h}$, 由于电池包质量非常大, 碰撞过程中会产 生巨大的惯性, 因此依旧从最大应力、弯曲变形以 及加速度三个方面对动力电池包的系统安全问题进 行分析。

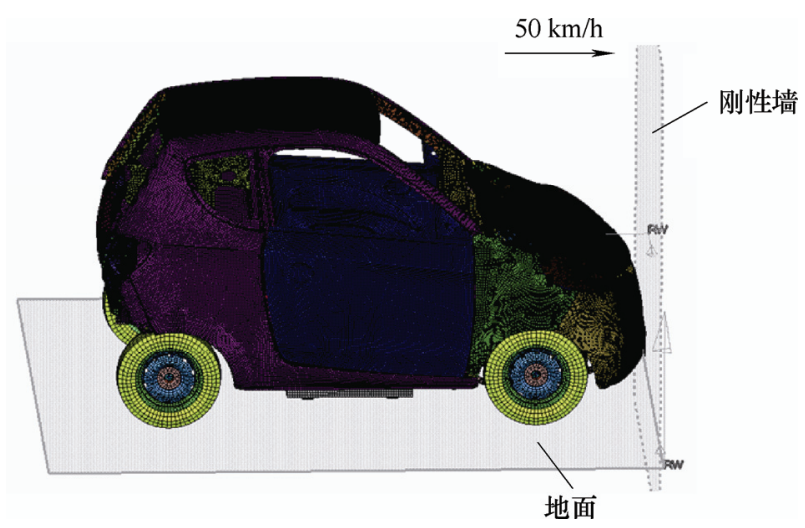

图 10 电动汽车整车刚性墙正面碰撞有限元模型

\subsubsection{1 最大应力}

由于正面碰撞产生较大的惯性, 电池包壳体吊 耳产生较大应力, 如图 11 所示, 正面碰撞工况下吊 耳应力比侧面碰撞工况下吊耳应力整体要小, 且各 
吊耳应力值更加集中, 变化趋势一致性更高。最大 吊耳应力值为 $401.9 \mathrm{MPa}$ ，与其材料抗拉强度 400 $\mathrm{MPa}$ 很接近, 吊耳发生断裂可能性较小。

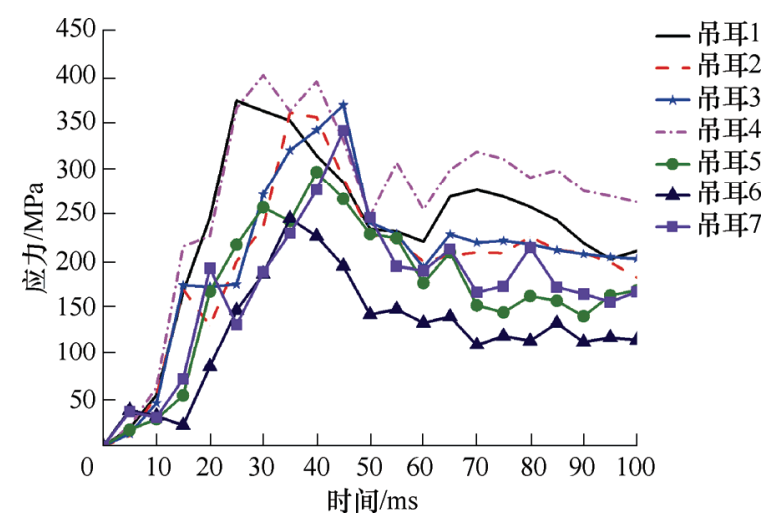

图 11 动力电池包正面碰撞吊耳应力变化图

\subsubsection{2 弯曲变形}

内架在碰撞过程中整体向车头方向倾斜变形, 尤其是与壳体底板焊接的部分。如图 12 中所示, 前 压杆在碰撞过程中产生了较为严重的弯曲变形, 内 架与壳体之间的焊点过少, 尤其是中架, 导致内架 与壳体底板连接刚度不足。从上面的分析可知, 最 先发生变形和变形量最大的内架部件为前压杆, 因 此应当改进电池包内架前压杆的设计缺陷。

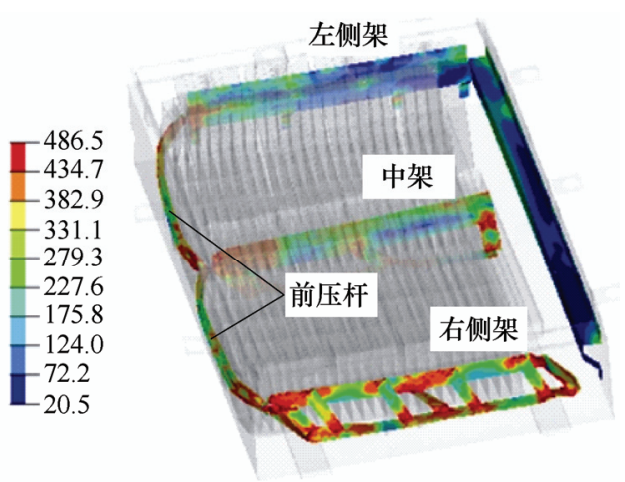

图 12 正面碰撞动力电池包内架应力云图

正面碰撞过程中, 在电池模组的大惯性带动下, 电池包内部垂直方向 $(Z$ 向)压紧结构发生了前倾, 尤其是内部中间部分。图 13 所示, 电池包内部上压 杆、上压盖以及长螺钉变形达到了最大, 但是上压 杆和上压盖的应力并不大, 主要就发生了较大的转 动和平动位移, 而压紧螺钉变形应力都较大。与侧 面碰撞工况下的长螺钉受力相比, 正碰压紧长螺钉 受力整体偏大, 大部分螺钉应力值都在 $400 \mathrm{MPa}$ 以 上, 最大值更是高达 $492.4 \mathrm{MPa}$, 已远远超过其材 料抗拉强度值, 会发生螺钉断裂现象, 甚至引起 电池包内部短路等。因此, 从正面碰撞角度考虑,
电池包内部 $Z$ 向压紧结构设计强度不足, 存在安全 隐患。

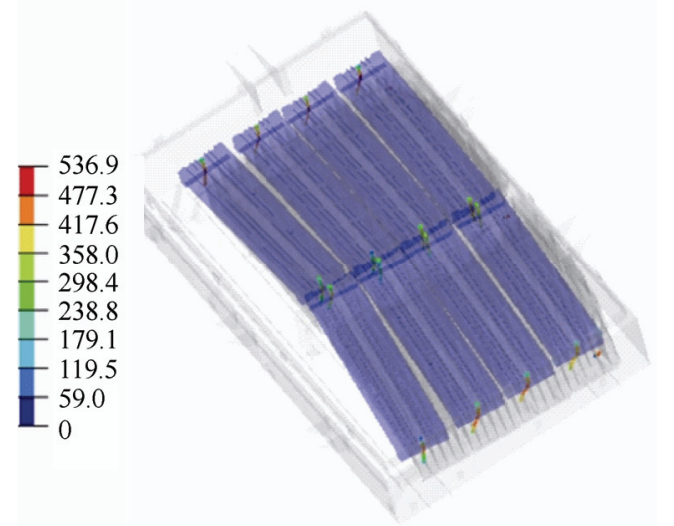

图 13 正面碰撞电池包内部 $Z$ 向压紧结构应力云图

\subsubsection{3 加速度分析}

正面碰撞工况下, 电池模组加速度响应情况, 如表 2 可知, 碰撞过程中所有电池模组加速度最大 的是模组 18 , 加速度值 $107.2 \mathrm{~g}$ 。虽然低于侧面碰撞 的最大加速度 $119.2 \mathrm{~g}$, 但是正面碰撞下所有模组加 速度值明显高于侧面碰撞下模组加速度值, 文献[20] 已说明电池单体或模组只能承受大小为 $35 g$ 的加速 度冲击。因此, 在正面碰撞工况下, 电池包内部模 组加速度冲击过大, 存在较大安全隐患。

表 2 正面碰撞过程中各电池模组加速度最大值

\begin{tabular}{cc||cc||cc}
\hline 编号 & 加速度 $/ g$ & 编号 & 加速度 $/ g$ & 编号 & 加速度 $/ g$ \\
\hline 1 & 73.2 & 9 & 94.9 & 17 & 106.9 \\
2 & 72.9 & 10 & 87.9 & 18 & $\mathbf{1 0 7 . 2}$ \\
3 & 76.1 & 11 & 77.4 & 19 & 103.5 \\
4 & 81.8 & 12 & 70.6 & 20 & 91.1 \\
5 & 90.9 & 13 & 104.0 & 21 & 90.0 \\
6 & 79.6 & 14 & 96.9 & 22 & 88.4 \\
7 & 74.2 & 15 & 87.5 & 23 & 90.2 \\
8 & 67.9 & 16 & 77.9 & 24 & 82.7 \\
\hline
\end{tabular}

\subsection{3 振动冲击状态的仿真分析}

振动冲击会对动力电池包内部结构造成疲劳损 伤, 还会对电池模组触点稳定性造成影响。通过动 应力和加速度两个指标研究动力电池包的振动冲击 系统安全性, 32 个带反馈信号线的关键电接触点位 置如图 14 所示。首先参考 GB/T 31467.3-2015《电 动汽车车用锂离子动力蓄电池包和系统 第 3 部分: 安全性要求与测试方法》中的振动试验要求, 对安 装在车辆成员仓下部的电池包分别施加 $X$ 轴、 $Y$ 轴、 $Z$ 轴稳态随机激励, 其 PSD 值如表 3 所示。冲 击工况为 $Z$ 轴施加 $25 \mathrm{~g} 、 15 \mathrm{~ms}$ 的半正弦波, 求解时 长设置为 $0.1 \mathrm{~s}$, 前 $15 \mathrm{~ms}$ 施加冲击激励, 后 $85 \mathrm{~ms}$ 观察激励去除后的自由振动。 


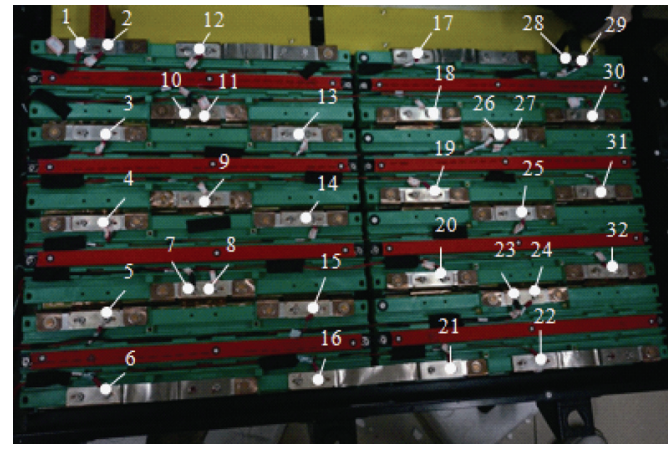

图 14 振动冲击状态下动力电池包模组关键触点

表 3 加载激励 PSD 值

\begin{tabular}{cccc}
\hline \multirow{2}{*}{ 频率 } & \multicolumn{3}{c}{ 功率谱密度 $(\mathrm{PSD}) /\left(\mathrm{g}^{2} / \mathrm{Hz}\right)$} \\
\cline { 2 - 4 } & $X$ 轴 & $Y$ 轴 & $Z$ 轴 \\
\hline 5 & 0.0125 & 0.01 & 0.05 \\
10 & 0.03 & 0.015 & 0.06 \\
20 & 0.03 & 0.015 & 0.06 \\
50 & $*$ & 0.01 & $*$ \\
200 & 0.00025 & 0.0004 & 0.0008 \\
$\mathrm{RMS} / g$ & 0.96 & 0.95 & 1.44 \\
\hline
\end{tabular}

\subsubsection{1 动应力分析}

通过施加 $X 、 Y 、 Z$ 轴稳态随机激励, 动力电 池包仿真得到的最大动应力分别在右侧内架与壳体 的前端焊点以及左侧内架与壳体的前端焊点, 对应 的 $3 \sigma_{F}$ 分别为 $82.8 \mathrm{MPa} 、 258.9 \mathrm{MPa} 、 359.1 \mathrm{MPa}$, 如图 15 所示。 $Y 、 Z$ 轴方向的最大动应力值都超过 了材料 Q235 的最大应力, 考虑到瞬时动应力超过 $235 \mathrm{MPa}$ 的概率不大, 可以认为动力电池包结构在 此工况下满足安全性, 如若可以改善内架与壳体前 端焊点的工艺, 可以有效地提升焊点的疲劳寿命。

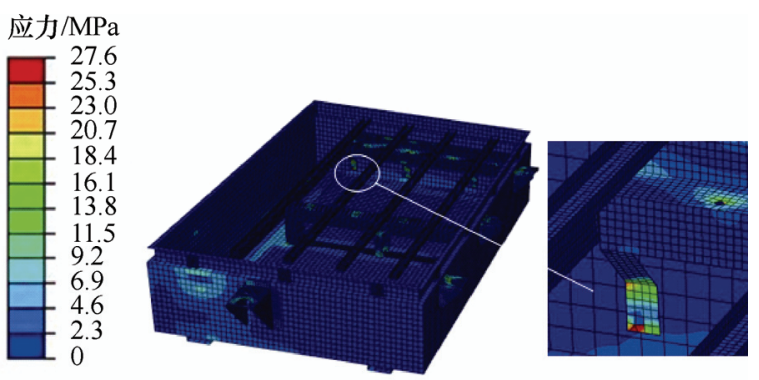

(a) $X$ 轴向激励最大应力云图
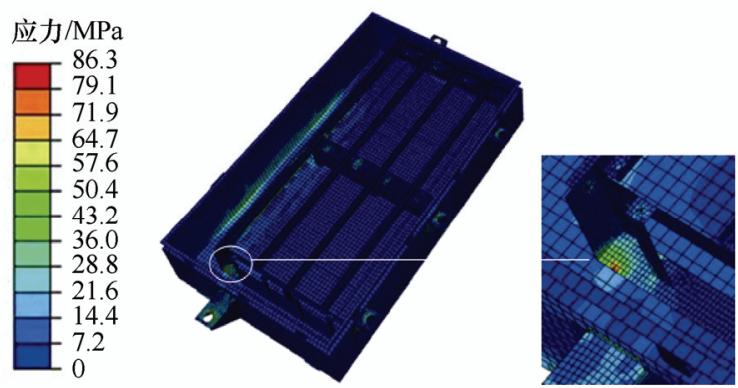

(b) $Y$ 轴向激励最大应力云图
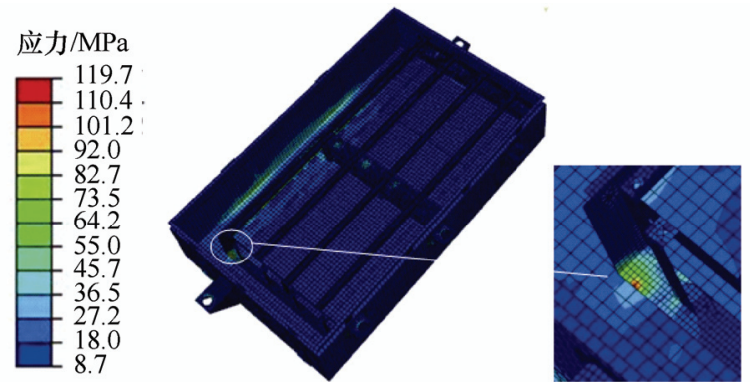

(c) Z轴向激励最大应力云图

图 15 稳态激励动力电池包壳体焊点应力分析

$X 、 Y 、 Z$ 轴稳态激励下, 电池模组的最大动 应力分别为 20 号触点的 $3.2 \mathrm{MPa} 、 10$ 号触点的 10.7 $\mathrm{MPa} 、 32$ 号触点的 $62.3 \mathrm{MPa}$; 对应的 $3 \sigma_{F}$ 分别为 9.6 $\mathrm{MPa} 、 32.1 \mathrm{MPa} 、 186.9 \mathrm{MPa}$, 如图 16 所示。大部 分时间内, 32 号触电的动应力值是低于 $186.9 \mathrm{MPa}$ 。

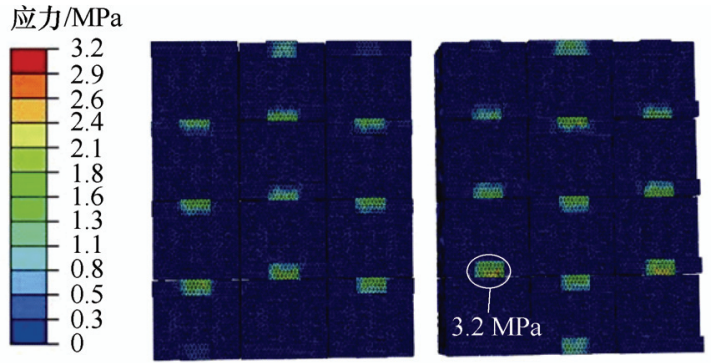

(a) $X$ 轴向激励模组触点最大应力云图

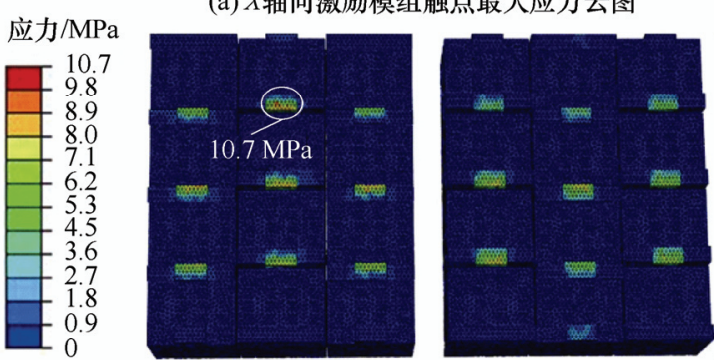

(b) $Y$ 轴向激励模组触点最大应力云图
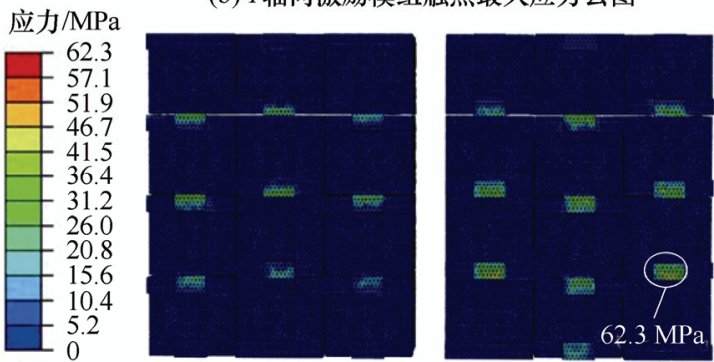

(c) $Z$ 轴向激励模组触点最大应力云图

图 16 稳态激励动力电池包模组触点最大动应力

施加冲击激励, 动力电池包壳体的位移响应呈 周期性变化, 如图 17a 所示。振动的形式为周期性 的上下反复振动, 最大应力达到 $231 \mathrm{MPa}$ 出现在 14 $\mathrm{ms}$, 与 $Z$ 轴稳态激励最大动应力点的位置一致。电 池模组触点应力在整个时域过程是交织变化的, 衰 减趋势基本一致, 并且在 $14 \mathrm{~ms}$ 左右出现最大值, 如图 17b、17c 所示。最大应力值出现在 20 号触点 
位置, 达到了 $140.4 \mathrm{MPa}$ 。冲击工况产生的交变应 力比稳态工况要高, 对系统内部的机械损伤更大,

因此对系统的可靠安全性要求更高。

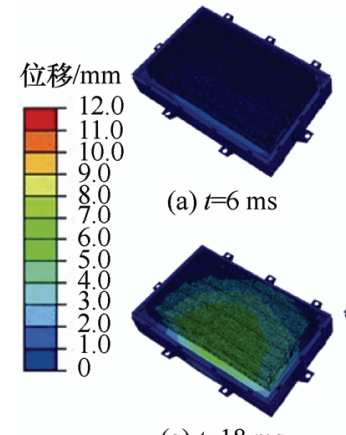

(a) $t=18 \mathrm{~ms}$

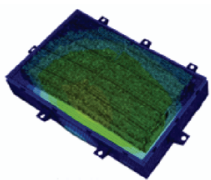

(b) $t=10 \mathrm{~ms}$

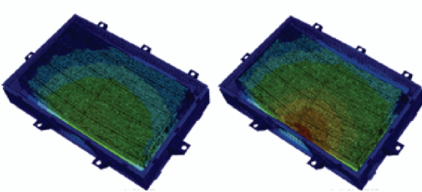

(b) $t=22 \mathrm{~ms}$

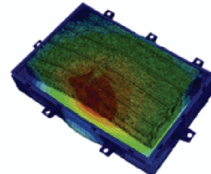

(c) $t=14 \mathrm{~ms}$

(c) $t=28 \mathrm{~ms}$ (a) 冲击工况下动力电池包位移时域变化
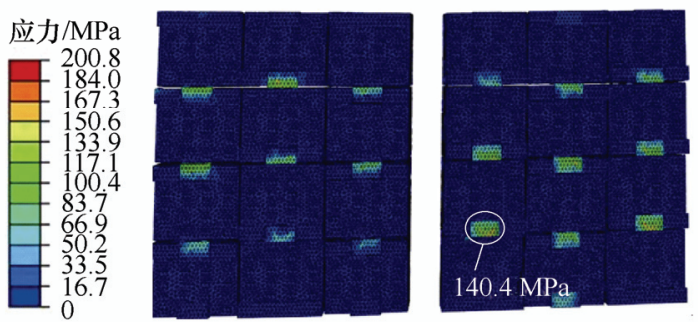

(b) $14 \mathrm{~ms}$ 动力电池包模组各触点应力

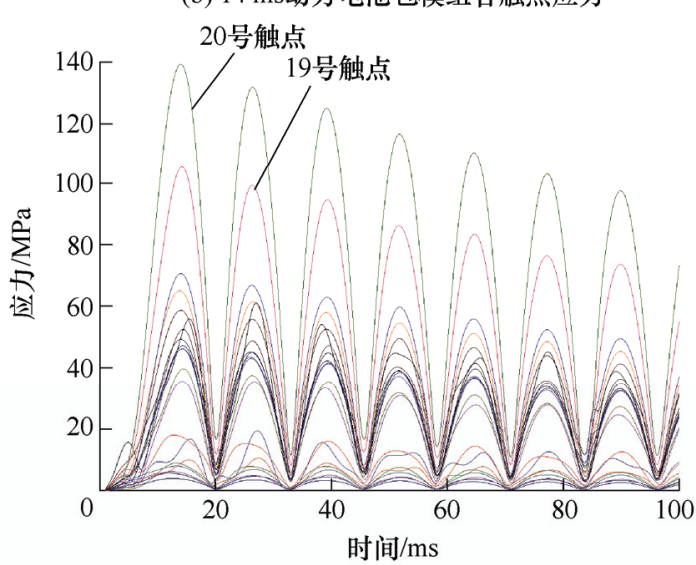

(c) 动力电池包模组各触点应力时域变化

图 17 瞬态激励动力电池包模组触点应力分析

\subsubsection{2 加速度分析}

施加 $X 、 Y 、 Z$ 轴激励, 动力电池包模组触点最 大加速度分别为 17 号触点 $2.8 g 、 12$ 号触点 $4.8 g$ 、 12 号触点 $18.9 \mathrm{~g}$, 根据图 $18 \mathrm{a}$ 可知不同位置触点的 加速度响应差异很大, 尤其 $Z$ 轴方向激励, 最大响 应 12 号触点 $18.9 g$, 最小响应 22 号触点 $1.8 g$, 呈现 很强的不均匀性。这样就导致动力电池包模组各个 触点稳定性和疲劳耐久有很大差异, 容易引发安全 问题。图 $18 \mathrm{~b}$ 是稳态激励下最大响应点的加速度功 率谱密度曲线, $Z$ 轴激励下最大响应位置出现在 39.4 $\mathrm{Hz}$, 与一阶模态频率非常接近。 $X$ 轴、 $Y$ 轴激励 下最大响应位置出现在 $81 \mathrm{~Hz}$ 和 $118 \mathrm{~Hz}$, 产生的 振型与电池模组在 $X 、 Y$ 运动方向引起动力电池包
的整体模态一致。可见电池组整体运动对触点的动 态响应影响很大。图 18c 所示, 冲击工况下电池模 组加速度响应分布与稳态工况相似, 但是响应值增 大很多, 其中较大的响应触点号为 $12 、 13 、 17,12$ 号触点最大响应值高达 $61.1 \mathrm{~g}$, 且 $100 \mathrm{~ms}$ 时, 响应 值仍达到 $33 g$, 由此可知动力电池包振动衰减能力 较差。

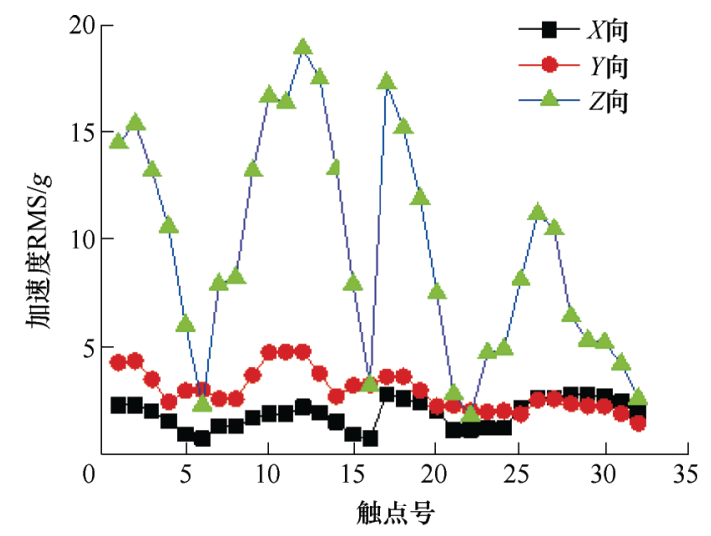

(a) 动力电池包模组触点位置加速度方均根值

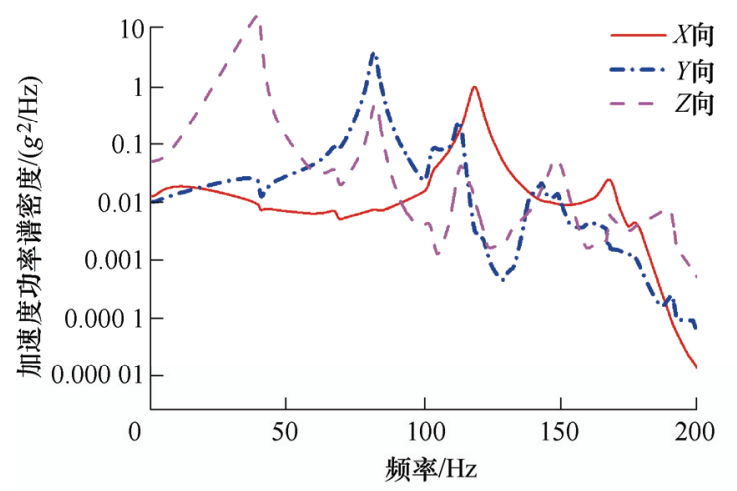

(b) 稳态工况动力电池包模组触点加速度频域分布

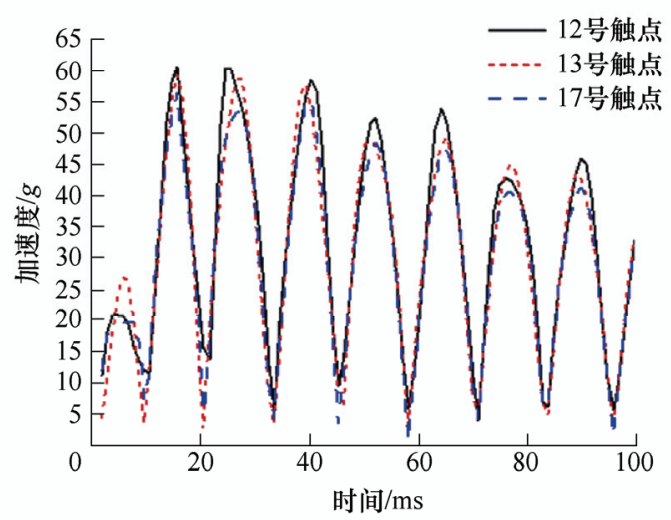

(c) 冲击工况12、13、17号触点加速度时域分布

图 18 振动冲击状态动力电池包模组触点加速度分析

通过对侧面刚性柱碰撞、正面 $100 \%$ 刚性墙碰 撞以及振动冲击三种工况的仿真, 从最大应力、弯 曲变形量、加速度三个方面对动力电池包系统安全 性进行研究分析, 提出 7 个影响整体安全的关键因 素指标, 分别为模组触点动应力; 模组触点加速度; 
内架弯曲变形; 壳体吊耳应力; 壳体焊接最大应力; 预紧螺栓最大应力; 壳体侵入量。通过对 7 个关键 因素指标的综合评价来对动力电池包的系统安全性 进行评判。

\section{3 机械外力下动力电池包系统安全的 综合评价方法}

过多的指标无法直观清晰地反映动力电池包的 系统安全性, 因此采用层次分析法(AHP)和模糊综 合评价(FCE)相结合的方法对动力电池包的系统安 全性进行综合评价。

\section{1 层次分析法}

层次分析法(AHP) 是针对复杂问题的本质, 通 过较少的定量信息并结合人的思维, 将问题内在 的关联关系构建成一个层次结构模型的方法。模 型的层次从上到下一般分为三类: 目标层、准则 层、方案层, 其中目标层表示整个方法的宗旨, 而准则层中的各准则在目标衡量中所占的比重并 不一定相同, 因此要确定其相对于上一层次支配 指标的相对重要性 ${ }^{[21]}$ 。也就是说, 以上一层指标 $\boldsymbol{B}$ 为准则, $\boldsymbol{B}$ 所支配的下一层指标评价对于准则 $e_{1}, e_{2}, \cdots, e_{n}$, 评价对于准则 $\boldsymbol{B}, e_{i}$ 和 $e_{j}$ 哪个更重要。 通过引入合适的标度将这种判断量化, 这样就可 以构建相应的判断矩阵。记 $n$ 阶矩阵 $\boldsymbol{A}=\left(a_{i j}\right)_{n \times n}$ 表示相对于指标 $e_{i}$ 和 $e_{j}$ 的支配指标 $\boldsymbol{B}$, 通过表 $1 \sim 4$ 可知, 引入量化指标 $e_{i}$ 比 $e_{j}$ 的重要或不重要 程度进行比较, 这种方法得到的矩阵 $\boldsymbol{A}$ 具有如下 性质

$$
\begin{cases}a_{i j}>0 & \\ a_{i i}=1 & i=1,2, \cdots, n ; j=1,2, \cdots, n \\ a_{i j}=\frac{1}{a_{j i}} & i \neq j\end{cases}
$$
矩阵。

由矩阵 $\boldsymbol{A}$ 满足式(6), 可知矩阵 $\boldsymbol{A}$ 是正互反

\section{2 动力电池包系统安全指标权重分析}

构建层次结构模型。目标层: 动力电池包系统 安全性 $S$, 准则层: 正面碰撞 $T_{1}$ 、侧面碰撞 $T_{2}$ 、振 动冲击 $T_{3}$, 方案层: 模组触点动应力 $C_{1}$ 、模组触点 加速度 $C_{2}$ 、内架弯曲变形 $C_{3}$ 、壳体吊耳应力 $C_{4}$ 、 壳体焊接最大动应力 $C_{5}$ 、预紧螺栓最大应力 $C_{6}$ 、壳 体侵入量 $C_{7}$, 如图 19 所示。根据层次分析法, 构 造各层次中所有的判断矩阵, 首先通过专家评判和 事故案例对各层次中的指标相对于上一层的指标进
行标度, 标度量由表 4 所提供 ${ }^{[22]}$ 。根据图 19 的层 次关系, 正面碰撞 $T_{1}$ 、侧面碰撞 $T_{2}$ 、振动冲击 $T_{3}$ 相 对于动力电池包系统安全性 $S$ 构建判断矩阵 $\boldsymbol{M}_{1}$, 然 后模组触点加速度 $C_{2}$ 、内架弯曲变形 $C_{3}$ 、壳体吊 耳应力 $C_{4}$ 、壳体焊接最大动应力 $C_{5}$ 、预紧螺栓最大 应力 $C_{6}$ 相对于正面碰撞 $T_{1}$ 构建判断矩阵 $\boldsymbol{M}_{2}$, 以此 可得到 4 个判断矩阵, 如矩阵 (7) (10)所示, 为保 证每个判断矩阵的一致性, 要通过一致性比例计算 公式 $C R=C I / R I<0.1$ 计算验证, 通过计算 $\boldsymbol{M}_{1}$ 、 $\boldsymbol{M}_{2} 、 \boldsymbol{M}_{3} 、 \boldsymbol{M}_{4}$ 的 $C R$ 值分别为: $0.033 、 0.084 、 0.098$ 、 0.046 均小于 0.1 , 因此上述判断矩阵均满足一致性 条件。

$$
\begin{gathered}
\boldsymbol{M}_{1}=\left(\begin{array}{ccc}
1 & 1 / 3 & 3 \\
3 & 1 & 5 \\
1 / 3 & 1 / 5 & 1
\end{array}\right) \\
\boldsymbol{M}_{2}=\left(\begin{array}{ccccc}
1 & 1 / 3 & 2 & 3 & 1 / 3 \\
3 & 1 & 2 & 2 & 1 / 2 \\
1 / 2 & 1 / 2 & 1 & 1 / 2 & 1 / 3 \\
1 / 3 & 1 / 2 & 2 & 1 & 1 / 2 \\
3 & 2 & 3 & 2 & 1
\end{array}\right) \\
\boldsymbol{M}_{3}=\left(\begin{array}{cccccc}
1 & 1 / 2 & 1 / 2 & 1 / 3 & 1 / 2 & 1 / 2 \\
2 & 1 & 1 / 2 & 3 & 2 & 1 / 3 \\
2 & 2 & 1 & 2 & 1 / 2 & 1 / 2 \\
3 & 1 / 3 & 1 / 2 & 1 & 1 / 2 & 1 / 3 \\
2 & 1 / 2 & 2 & 2 & 1 & 1 / 3 \\
2 & 3 & 2 & 3 & 3 & 1
\end{array}\right) \\
\boldsymbol{M}_{4}=\left(\begin{array}{ccc}
1 & 2 & 1 / 3 \\
1 / 2 & 1 & 1 / 3 \\
3 & 3 & 1
\end{array}\right)
\end{gathered}
$$

表 4 指标量化评价准则

\begin{tabular}{ccc}
\hline 重要性等级 & 相应的 $a_{i j}$ 的值 & \multicolumn{1}{c}{ 说明 } \\
\hline$e_{i}$ 比 $e_{\mathrm{j}}$ 极端重要 & 9 & $\begin{array}{l}\text { 两指标的判断差异达到 } \\
\text { 可能范围内的最大限度 }\end{array}$ \\
$e_{i}$ 比 $e_{\mathrm{j}}$ 强烈重要 & 7 & $\begin{array}{l}\text { 两指标的判断差异强烈 } \\
e_{i} \text { 比 } e_{\mathrm{j}} \text { 明显重要 }\end{array} e^{\text {两指标的判断差异明显 }}$ \\
$e_{i}$ 比 $e_{\mathrm{j}}$ 稍重要 & 5 & 两指标的判断差异轻微 \\
$e_{i}$ 比 $e_{\mathrm{j}}$ 同等重要 & 1 & 两指标无判断差异 \\
$e_{i}$ 比 $e_{\mathrm{j}}$ 稍不重要 & $1 / 3$ & 两指标的判断差异轻微 \\
$e_{i}$ 比 $e_{\mathrm{j}}$ 明显不重要 & $1 / 5$ & 两指标的判断差异明显 \\
$e_{i}$ 比 $e_{\mathrm{j}}$ 强烈不重要 & $1 / 7$ & 两指标的判断差异强烈 \\
$e_{i}$ 比 $e_{\mathrm{j}}$ 极端不重要 & $1 / 9$ & 两指标的判断差异达到 \\
\hline
\end{tabular}




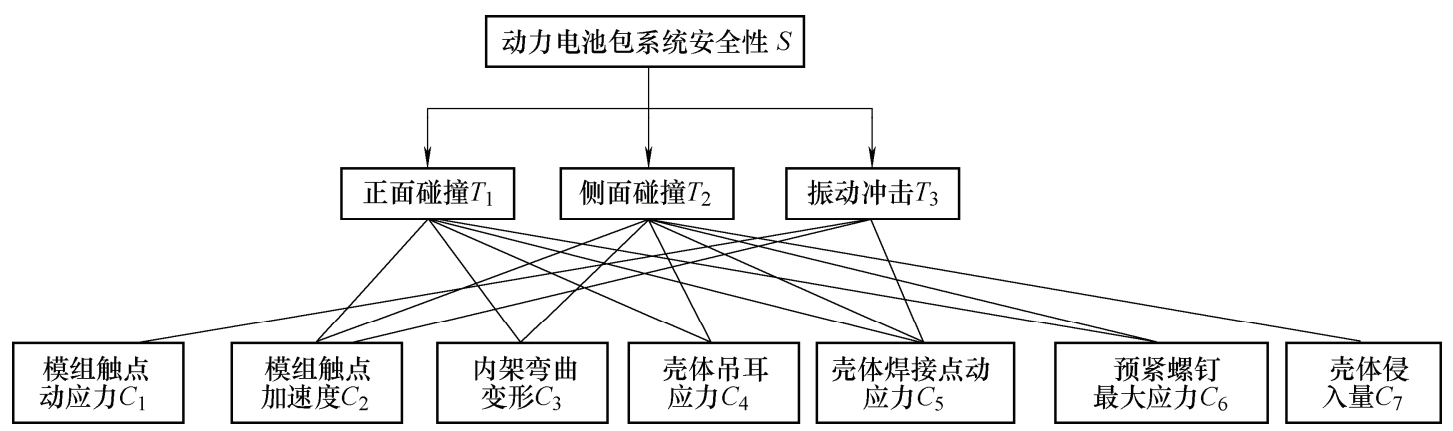

图 19 机械外力下动力电池包系统安全性分析递阶层次结构图

完成一致性验证后, 计算层与层之间指标的权 重系数, 例如: 判断矩阵 $\boldsymbol{M}_{1}$ 可以得到正面碰撞 $T_{1}$ 、 侧面碰撞 $T_{2}$ 、振动冲击 $T_{3}$ 相对于动力电池包系统安 全性 $S$ 的指标权重系数：0.258、0.637、0.105, 同 理可得到 $\boldsymbol{M}_{2} 、 \boldsymbol{M}_{3} 、 \boldsymbol{M}_{4}$ 判断矩阵的权重系数, 由 图 19 所示结构, 第 $k-1$ 层 $n_{k-1}$ 个指标相对于最高 层指标的权重向量 $\left(\boldsymbol{\alpha}_{1}, \boldsymbol{\alpha}_{2}, \cdots, \boldsymbol{\alpha}_{n_{k-1}}\right)$, 第 $k$ 层上个指 标对第 $k-1$ 层的第 $j$ 个指标的权重向量为 $\left(\boldsymbol{\beta}_{1 j}, \boldsymbol{\beta}_{2 j}, \cdots, \boldsymbol{\beta}_{n_{k-1}}\right)$, 其中不受第 $j$ 个指标支配的指 标的权重为 0 , 则第 $k$ 层上指标相对于最高层指标 的权重矢量为

$$
\boldsymbol{\omega}_{i}=\sum_{j=1}^{n_{k-1}} \boldsymbol{\beta}_{i j} \boldsymbol{\alpha}_{j} \quad i=1,2, \cdots, n_{k}
$$

根据式(9)可以计算出方案层相对于目标层的 权重向量, 得到最底层 7 项指标相对于最高层动力 电池包系统安全性 $S$ 的指标权重 $\left(\omega_{1}, \omega_{2}, \cdots, \omega_{7}\right)$, 如 表 5 所示。根据表 5 可以看出, 壳体侵入量 $\omega_{7}$ 的权 重系数最大, 这是由于碰撞状态下的壳体侵量不仅 导致内架弯曲变形, 而且挤压模组以及单体电池等, 很容易导致动力电池包出现安全问题, 因此权重系 数偏高。

表 5 动力电池包系统安全指标权重

\begin{tabular}{cccccccc}
\hline & $\begin{array}{c}\text { 模组 } \\
\text { 指标 }\end{array}$ & $\begin{array}{c}\text { 模组 } \\
\text { 触点 }\end{array}$ & $\begin{array}{c}\text { 内触点 } \\
\text { 弯曲 }\end{array}$ & $\begin{array}{c}\text { 壳体 } \\
\text { 吊耳 }\end{array}$ & $\begin{array}{c}\text { 壳体焊接 } \\
\text { 最大 }\end{array}$ & $\begin{array}{c}\text { 预紧 } \\
\text { 螺栓 }\end{array}$ & $\begin{array}{c}\text { 壳体 } \\
\text { 权重 }\end{array}$ \\
$\begin{array}{ccccccc}\text { 动应力 } \\
\text { 加速度 }\end{array}$ & $\begin{array}{c}\text { 变形 } \\
\omega_{1}\end{array}$ & $\begin{array}{c}\omega_{2} \\
\omega_{3}\end{array}$ & $\begin{array}{c}\omega_{4} \\
\text { 动应力 }\end{array}$ & $\begin{array}{c}\text { 最大应力 } \\
\omega_{5}\end{array}$ & $\omega_{6}$ & $\omega_{7}$ \\
\hline 系数 & 0.026 & 0.111 & 0.177 & 0.131 & 0.159 & 0.193 & 0.203 \\
\hline
\end{tabular}

\section{3 机械外力下动力电池包系统安全模糊综合评价}

\subsection{1 评价指标分级}

(1) 侧面碰撞导致动力电池包壳体变形, 最大 侵入量达到了 $52.8 \mathrm{~mm}$, 要保证变形不能对内部组 件造成挤压伤害, 因此最大变形 为 $38.5 \mathrm{~mm}$ 。

(2) 预紧螺钉在碰撞过程中也产生了一定的变 形, 保证螺钉不失效, 以屈服强度和极限强度对其 进行等级划分。
（3）电池壳体的吊耳在碰撞过程中也产生了很 大的应力, 保证吊耳不破坏, 以屈服强度和极限强 度对其进行等级划分。

(4) 内部支架产生的变形以不能挤压到电池系 统为划分原则。

(5) 振动冲击导致壳体的焊接处以及电池模组 的触点都产生了动应力, 不仅如此, 电池模组触点 处还产生了均匀性较差的触点加速度。为了对壳体 焊点动应力、模组触点动应力和加速度进行等级划 分, 要先对这 3 个指标进行针对性处理, 由于电动 汽车实际作业过程当中，随机稳态路面占汽车行驶 的大部分工况, 在此 $f_{1}$ 代表随机稳态工况, $f_{2}$ 代表 瞬态冲击工况, 其相应的权重值, 根据文献研究取 $f_{1}=0.8 、 f_{2}=0.2$, 例如稳态工况下壳体 $Z$ 方向的 最大动应力值: $f_{1} \times \sigma / n, \sigma$ 是 $\mathrm{Q} 235$ 的屈服强度, $n$ 是疲劳设计安全系数。

将上述 7 个评价指标划分为 $v_{1} 、 v_{2}$ 和 $v_{3}$ 三个等 级。其中 $v_{1}$ 级表示动力电池包系统安全性较高; $v_{3}$ 级 表示很差, 说明机械外力下动力电池包系统安全性 较低, 在碰撞、振动冲击工况下均可能发生安全事 故, 提升安全性的空间较大; $v_{2}$ 级介于 $v_{1}$ 与 $v_{3}$ 之间, 表示其系统安全性一般, 在各种状态下发生事故的 概率不大有一定的安全性提升空间。表 6 列举了 7 个指标的评价分级。

表 6 动力电池包系统安全指标评价分级

\begin{tabular}{cccccccc}
\hline 评价 & $C_{1} /$ & $C_{2} /$ & $C_{3} /$ & $C_{4} /$ & $C_{5} /$ & $C_{6} /$ & $C_{7} /$ \\
指标 & $\mathrm{MPa}$ & $g$ & $\mathrm{~mm}$ & $\mathrm{MPa}$ & $\mathrm{MPa}$ & $\mathrm{MPa}$ & $\mathrm{mm}$ \\
\hline$v_{1}$ & $<19$ & $<5 g$ & $<20$ & $<235$ & $<62$ & $<235$ & $<24$ \\
$v_{2}$ & $19 \sim 50$ & $5 g \sim 12 g$ & $20 \sim 50$ & $235 \sim 400$ & $62 \sim 125$ & $235 \sim 400$ & $24 \sim 38.5$ \\
$v_{3}$ & $>50$ & $>12 g$ & $>50$ & $>400$ & $>125$ & $>400$ & $>38.5$ \\
\hline
\end{tabular}

3.3.2 隶属度函数的确定

单项指标的变化规律是确立隶属度函数的必要 条件, 针对各指标的实际情况对其进行赋值, 有时 会出现在分级临界值附近，此时等级之间数值的相 关性不大，但是等级的评价完全不同，为消除这种 
跳跃的现象对其进行模糊化处理 ${ }^{[23]}$ 。令 $v_{2}$ 级中点处 的隶属度为 1 , 两侧临界点隶属度为 0.5 , 中间向两 侧纯属递减。令 $v_{1}$ 和 $v_{2}$ 级临界值为 $k_{1}, v_{2}$ 和 $v_{3}$ 级临 界值为 $k_{3}, v_{2}$ 级中间值为 $k_{2}$, 且有 $k_{2}=\left(k_{1}+k_{2}\right) / 2$ 。 隶属度函数计算公式如下

$$
\begin{aligned}
& \mu_{v_{1}}= \begin{cases}0.5\left(1+\frac{k_{1}-C_{i}}{k_{2}-C_{i}}\right) & C_{i}<k_{1} \\
0.5\left(1-\frac{C_{i}-k_{1}}{k_{2}-k_{1}}\right) & k_{1} \leqslant C_{i}<k_{2} \\
0 & C_{i} \geqslant k_{2}\end{cases} \\
& \mu_{v_{2}}= \begin{cases}0.5\left(1-\frac{k_{1}-C_{i}}{k_{2}-C_{i}}\right) & C_{i}<k_{1} \\
0.5\left(1+\frac{C_{i}-k_{1}}{k_{2}-k_{1}}\right) & k_{1} \leqslant C_{i}<k_{2} \\
0.5\left(1+\frac{k_{3}-C_{i}}{k_{2}-k_{1}}\right) & k_{2} \leqslant C_{i}<k_{3} \\
0.5\left(1-\frac{k_{3}-C_{i}}{k_{2}-C_{i}}\right) & C_{i} \geqslant k_{3}\end{cases} \\
& \mu_{v_{3}}= \begin{cases}0.5\left(1+\frac{k_{3}-C_{i}}{k_{2}-C_{i}}\right) & C_{i} \geqslant k_{3} \\
0.5\left(1-\frac{C_{i}-k_{3}}{k_{2}-k_{3}}\right) & k_{2} \leqslant C_{i}<k_{3} \\
0 & C_{i}<k_{2}\end{cases}
\end{aligned}
$$

根据上述隶属度公式计算动力电池包系统安全 指标隶属度矩阵 $\boldsymbol{R}$

$$
\boldsymbol{R}=\left(\begin{array}{ccc}
0.375 & 0.551 & 0.074 \\
0.224 & 0.478 & 0.298 \\
0.773 & 0.227 & 0 \\
0 & 0.823 & 0.177 \\
0.292 & 0.570 & 0.138 \\
0 & 0.425 & 0.575 \\
0 & 0.168 & 0.823
\end{array}\right)
$$

利用上文求解的权重矢量 $\boldsymbol{\omega}$ 与隶属度函数矩 阵 $\boldsymbol{R}$ 进行合成, 可得到动力电池包多状态系统安全 综合评价结果 $\boldsymbol{S}$ ，即

$$
\boldsymbol{S}=\boldsymbol{\omega} \times \boldsymbol{R}=\left\{\begin{array}{lll}
0.081 & 0.413 & 0.506
\end{array}\right\}
$$

根据综合评价向量 $\boldsymbol{S}$ 可知, $v_{1}$ 级 $<v_{2}$ 级 $<v_{3}$ 级, 这就说明动力电池包系统安全性等级较低, 安全性 能差, 在发生机械外力事故时电池包发生短路、起 火以及爆炸的可能性较高。

\section{4 结论}

(1) 单一的提升动力电池包各个组件的可靠安 全性并不能改善其系统安全性, 采用复杂系统认知 下的动力电池包安全性研究与评价方法, 不仅考虑 各个组件的可靠安全性, 组件之间的潜在耦合关系 也被相应的考虑。

（2）构建动力电池包整体精细化有限元模型, 其中包括开发单体电池的精细化有限元模型。使用 力学试验和模态试验对相应的有限元模型给予验 证, 确保所有模型精度的情况下进行正碰、侧碰及 振动冲击的仿真分析。

(3) 利用层次分析法对 7 个关键因素指标进行 权重分析, 以模糊综合评价理论方法为基础, 建立 隶属度函数, 对动力电池包系统安全性进行定量评 价。根据指标的评价结果可知机械外力下动力电池 包系统安全性较差, 电池包发生起火、爆炸的可能 性较高。此方法可为动力电池包正向结构设计和系 统安全改善等工作提供参考。

\section{参 考 文 献}

[1] 张剑波, 卢兰光, 李哲. 车用动力电池系统的关键技术 与学科前沿 $[\mathrm{J}]$. 汽车安全与节能学报, 2012, 3(2): 87-104.

ZHANG Jianbo, LU Guanglan, LI Zhe. Key technologies and fundamental academic issues for traction battery systems[J]. Journal of Automotive Safety and Energy, 2012, 201(1): 307-321.

[2] 刘佳. 碰撞工况下电动客车动力电池系统安全控制研 究[D]. 北京: 北京理工大学, 2015 .

LIU Jia. Study on security control electric bus power battery system on collision conditions[D]. Beijing: Beijing Institute of Technology, 2015.

[3] HOLLNAGEL E. Barriers and accident prevention[M]. London: Routledge, 2004.

[4] 王力, 邓雄志, 陈家设. 基于结构优化的混合动力轿车 电池包模态特性改进[J]. 上海汽车, 2014(6): 3-6.

WANG Li, DENG Xiongzhi, CHEN Jiashe. Improvement of modal characteristic of battery pack of hybrid electric car based on structural optimization[J]. Shanghai Auto, 2014(6): 3-6.

[5] 符兴锋, 翟艳霞, 肖莎, 等. 增程式纯电动汽车动力电 池高压电安全管理[J]. 汽车技术, 2014(10): 44-49. FU Xingfeng, ZHAI Yanxia, XIAO Sha, et al. Power battery high voltage safety management for extended ranged electric vehicle[J]. Automobile Technology, 
2014(10): 44-49.

[6] CHEN S C, WAN C C, WANG Y Y. Thermal analysis of lithium-ion batteries[J]. Journal of Power Sources， 2005, 140(1): 111-124.

[7] 孙小卯. 某型电动汽车电池包结构分析及改进设计 [D]. 长沙: 湖南大学, 2013.

SUN Xiaomao. Structure analysis and improvement design of battery pack in electric vehicle[D]. Changsha: Hunan University, 2013.

[8] 张立军, 陈华杰, フ坤, 等. 电动汽车动力电池振动与 冲击问题研究综述 [J]. 电源技术, 2013, 37(1): 156-159. ZHANG Lijun, CHEN Huajie, DIAO Kun, et al. Review of vibration and shock dynamics of electric vehicles battery[J]. Chinese Journal of Power Sources, 2013, 37(1): 156-159.

[9] STROEVE S H, BLOM H A P, BAKKER G J. System accident risk assessment in air traffic by Monte Carlo simulation[J]. Safety Science, 2009, 47(2): 238-249.

[10] LEVESON N G. System safety engineering: Back to the future[M]. Boston: Aeronautics and Astronautics Massachusetts Institute of Technology，2002.

[11] 何向明, 冯旭宁, 欧阳明高. 车用锂离子动力电池系统 的安全性[J]. 科技导报，2016，34(6): 32-36.

HE Xiangming, FENG Xuning, OUYANG Minggao. The system safety of lithium-ion battery for vehicle[J]. Science \& Technology Review, 2016, 34(6): 32-36.

[12] LEVESON N G. Engineering a safer world, systems thinking applied to safety[M]. Cambridge: The MIT Press, 2012.

[13] KRZYSZTOF K, JOANNA S. Reliability and safety of complex technical systems and processes[M]. London: Springer, 2011.

[14] SAHRAEI E, HILL R, WIERZBICKI T. Calibration and finite element simulation of pouch lithium-ion batteries for mechanical integrity[J]. Journal of Power Sources, 2012, 201(1): 307-321.

[15] SAHRAEI E, MEIER J, WIERZBICKI T. Characterizing and modeling mechanical properties and onset of short circuit for three types of lithium-ion pouch cells[J]. Journal of Mechanical Engineering, 2014, 247(1): 503-516

[16] AVDEEV I , GILAKI M. Structural analysis and experimental characterization of cylindrical lithium-ion battery cells subject to lateral impact[J]. Journal of Power Sources, 2014, 271(20): 382-391.
[17] 赵猛, 张以都, 马良文, 等. 装配结构模态仿真与实验 对比研究 [J]. 振动与冲击, 2005，24(1): 28-29.

ZHAO Meng, ZHANG Yidu, MA Liangwen, et al. Research on modal analysis of assembly structures based on MSC/Nastran[J]. Journal of Vibration and Shock, 2005, 24(1): 28-29.

[18] 谈卓君, 廖日东, 左正兴, 等. 接触条件下组合结构的 动力学分析 $[\mathrm{J}]$. 机械强度, 2006, 28(5): 658-663.

TAN Zhuojun, NIAO Ridong, ZUO Zhengxing, et al. Dynamic analysis of composite structure on contact condition[J]. Journal of Mechanical Strength, 2006, 28(5): 658-663.

[19] 崔佳. 电动客车侧向被动安全仿真与结构优化研究[D]. 北京: 北京理工大学，2015.

CUI Jia. Research on side passive safety for electric bus with simulation and structure optimization[D]. Beijing: Beijing Institute of Technology, 2015.

[20] SINZ W, BREITFUß C, TOMASCH E, et al. Integration of a crashworthy battery in a fully electric city bus $[\mathrm{J}]$. International Journal of Crashworthiness, 2012, 17(1): 105-118.

[21] 邓雪, 李家铭, 曾浩健, 等. 层次分析法权重计算方法 分析及其应用研究 $[\mathrm{J}]$. 数学的实践与认识, 2012 , 42(7): 93-99.

DENG Xue, LI Jiaming, ZENG Haojian, et al. Research on computation methods of AHP wight vector and its applications $[\mathrm{J}]$. Mathematics in Practice and Theory, 2012, 42(7): 93-99.

[22] 费智聪. 熵权-层次分析法与灰色-层次分析法研究[D]. 天津：天津大学， 2009.

FEI Zhicong. Research on entropy weight-analytic hierarchy process and grey-analytic hierarchy process $[\mathrm{J}]$. Tianjin: Tianjin university, 2009.

[23] 卜楠楠, 唐德善, 尹笋. 基于 AHP 法的浙江省水资源 承载力模糊综合评价 [J]. 水电能源科学, 2012, 30(3): 42-44.

BU Nannan, TANG Deshan, YIN Sun. Fuzzy comprehensive evaluation of carrying capacity of water resources in Zhejiang province based on AHP method[J]. Water Resources and Power, 2012, 30(3): 42-44.

作者简介: 李志杰, 男, 1986 年出生, 博士研究生。主要研究方向为新 能源汽车电池系统安全。

E-mail: heaton_1zj@163.com

兰风崇(通信作者), 男, 1959 年出生, 博士, 教授, 博士研究生导师。 主要研究方向为汽车现代设计方法、汽车车身结构与安全。

E-mail: fclan@scut.edu.cn 